\title{
Prevalence and antimicrobial susceptibility of extended-spectrum beta lactamases-producing Escherichia coli and Klebsiella pneumoniae isolated in selected hospitals of Anyigba, Nigeria
}

\author{
Kehinde C Mofolorunsho ${ }^{1}$, Hannah O Ocheni ${ }^{1}$, Ruth F Aminu ${ }^{1}$, Cornelius A Omatola ${ }^{1}$, Olabisi O Olowonibi ${ }^{2}$
}

1. Kogi State University, Faculty of Natural Sciences, Department of Microbiology.

2. Tshwane University of Technology, Department of Pharmaceutical Science.

\begin{abstract}
Background: Escherichia coli and Klebsiella pneumoniae are commonly implicated in urinary tract infections accounting for majority of the antimicrobial resistance encountered in hospitals.

Objectives: To determine the prevalence and antimicrobial susceptibility of extended-spectrum beta-lactamases (ESBLs) producing E. coli and K. pneumoniae among patients in Anyigba, Nigeria.

Methods: This hospital-based cross-sectional study was conducted using urine samples from 200 patients of Grimmard Catholic hospital and Maria Goretti hospital. Urine samples were processed to identify ESBL-producing E. coli and K. pneumoniae using standard microbiological techniques. Isolates were then tested against antimicrobial agents.

Results: A total of 156 bacterial isolates were recovered consisting 128 of E. coli and 28 of $K$. pneumoniae. Extended spectrum beta-lactamases production was observed in $69 \%$ of E. coli and $31 \%$ of $K$. pneumoniae. These pathogens were resistant to 3 or more antibiotics. Of the antimicrobials tested, cefotaxime demonstrated the highest rates of resistance $(100 \%)$ for both ESBL-producing E. coli and K. pneumoniae. Fifty-four isolates of ESBL-producing E. coli showed a high level of resistance to amoxicillin clavulanic acid (83.3\%), ciprofloxacin (83.3\%), and ceftazidime (79.6\%). ESBL-positive K. pneumoniae isolates were highly resistant to ciprofloxacin (75\%), and amoxicillin clavulanic acid $(83.3 \%)$. Cefoxitin $(62.5 \%)$ and gentamicin $(66.7 \%)$ showed substantially higher rates of resistance against these isolates while all 24 strains were resistant to imipenem. Conclusion: This study indicated the prevalence of ESBL-positive Gram-negative pathogens in these study sites and also demonstrated their resistance to a few antibiotics. This highlights the need for new antimicrobials that are potent and improved policy on use of antibiotics.
\end{abstract}

Keywords: Antibiotic resistance, ESBLs, Escherichia coli, Klebsiella pneumoniae, Anyigba.

DOI: https://dx.doi.org/10.4314/ahs.v21i2.4

Cite as: Mofolorunsho KC, Ocheni HO, Aminu RF, Omatola CA, Olowonibi OO. Prevalence and antimicrobial susceptibility of extended-spectrum beta lactamases-producing Escherichia coli and Klebsiella pneumoniae isolated in selected hospitals of Anyigba, Nigeria. Afri Health Sci. 2021;21(2). 505-512. https:/ / dx.doi.org/10.4314/abs.v21i2.4

\section{Introduction}

About 1.5 billion infections due to microorganisms have been reported to occur globally each year resulting in approximately 4.6 million deaths ${ }^{1}$. Several previous studies have highlighted the magnitude of infectious diseases in the human population with reports of an estimated 106 million cases of gonorrhoea, 3.1 million cases of lower respiratory infections and 1.5 million cases of diarrheal diseases globally ${ }^{2,3}$. This is worrisome and

\section{Corresponding author: \\ Kehinde C Mofolorunsho, \\ Department of Microbiology Faculty of Natural \\ Sciences Kogi State University \\ P.M.B 1008, Anyigba, Nigeria \\ Tel: +2348034793137 \\ E-mail: mofolorunsho.ck@ksu.edu.ng}

of major concern especially in hospital settings particularly for critically ill patients and for patients requiring placement of invasive devices or surgical procedures ${ }^{4,5}$. The global spread of antimicrobial resistance among bacterial pathogens is a serious threat to human health and a challenge for modern medicine with significant impact on health care $\cos ^{6,7}$. A recent report estimated that 10 million deaths will be attributed to antimicrobial resistance by 2050 and 100 trillion USD of the world's economic outputs will be lost if substantive efforts are not made to contain this threat ${ }^{8-10}$. Little wonder the World Health Organization identified antimicrobial resistance as one of the three greatest threats to mankind in the $21^{\text {st }}$ century ${ }^{11,12}$. Studies conducted over the years, have identified some Gram-negative pathogens as a major cause of hospital-acquired infections (HAIs) especially in developing countries. These pathogens have accounted for majority of the antimicrobial resistance

(C) 2021 Mofolorunsho KC et al. Licensee African Health Sciences. This is an Open Access article distributed under the terms of the Creative commons Attribution License (https://creativecommons.org/licenses/BY/4.0), which permits unrestricted use, distribution, and reproduction in any medium, provided the original work is properly cited. 
encountered in hospital settings and has presented serious therapeutic dilemmas for clinicians due to complex resistance profiles resulting in high morbidity and mortality rates as well as prolonged hospital stay ${ }^{4,5,13}$.

Several resistant Gram-negative bacterial pathogens producing extended-spectrum beta-lactamases (ESBLs) have been increasingly involved in hospital-acquired infections resulting in a dearth of treatment options. Extended-spectrum beta-lactamases (ESBLs) are enzymes encoded on the chromosome or on plasmids, conferring resistance to penicillins, cephalosporins, and monobactams ${ }^{14,15}$. The burden of ESBL is currently of global concern to humans, just as is animals and the ecosystem $^{16-19}$. Of particular concern is the emergence of ESBL-producing Klebsiella pneumoniae in hospital settings ${ }^{20}$ which has considerably increased during the last decade, and ESBL-producing Escherichia coli; a leading cause of blood stream and urinary tract infections (UTIs) capable of hydrolysing numerous antibiotics, including third generation cephalosporins ${ }^{6}$. K. pneumoniae is the second most common cause of UTIs after E. coli, often due to the use of indwelling catheters ${ }^{21}$. Urinary tract infections are one of the most common infections encountered in medical practice affecting a large patient population irrespective of age and gender with a global prevalence estimated to be around 150 million persons per year ${ }^{22-24}$.

The World Health Organization's global surveillance report on antibiotic resistance indicated that five out of the six WHO regions had more than $50 \%$ resistance to third generation cephalosporins in E. coli and K. pneumoniae in hospital settings. The report also revealed that $K$. pneumoniae resistant to third generation cephalosporins was associated with elevated deaths in Africa (77\%), the Eastern Mediterranean region (50\%), South East Asia $(81 \%)$ and Western Pacific region (72\%). It further attributed $45 \%$ of deaths in both Africa and South-East Asia to multi-drug resistant (MDR) bacteria. These resistant strains are considered a public health issue $e^{10,25,26}$ and calls for attention.

In Nigeria, indiscriminate use of antibiotics, poor hygiene practices in hospitals settings and the lack of monitoring of antimicrobial resistant microorganisms have been associated with the emergence and uncontrolled spread of $\mathrm{ESBLs}^{27}$ resulting in treatment failures, increased morbidity and mortality rates. The objectives of this study were therefore to determine the presence of E. coli and K. pneumoniae in urine samples collected from hospital patients in Anyigba a community in North
Central Nigeria by conventional culture and biochemical analyses. The prevalence and antibiotic susceptibility profile of ESBL-producing clinical isolates were also investigated to ascertain the magnitude of ESBL carriage in order to improve the antibiotic management of hospital-acquired infections in the community.

\section{Methodology \\ Study area}

This cross-sectional hospital-based study was conducted in Anyigba, a community in Dekina Local Government of Kogi State, Nigeria. The population of the community which lies between latitude 7o15'-7o29' north and longitude $7^{\circ} 11^{\prime}-7^{\circ} 32^{\prime}$ east with an average altitude of $420 \mathrm{~m}$ above sea level, is estimated at $130,000^{28}$.

\section{Ethical consideration}

Ethical approval was obtained from the hospitals' management board on ethics relating to health issues in line with the Declaration of Helsinki on the conduct of biomedical research involving human subjects. All participants gave their consent to enter the study.

\section{Sample collection}

Two hundred samples of urine were collected from both inpatients and out-patients of the Grimmard Catholic Hospital (GCH) and Maria Goretti Hospital (MGH) in Anyigba, North-Central Nigeria between May and October 2018. These frequently utilized private primary healthcare facilities, takes care of the majority of medical cases within the community.

Mid-stream urine samples were collected into sterile universal bottles and immediately transported to the Kogi State University's Microbiology laboratory for analyses. Information on sex and age were obtained from patients' hospital records. All samples were streaked onto MacConkey agar (Oxoid, UK) containing ceftazidime $(1 \mathrm{mg} / \mathrm{L})$. Incubation was at $37^{\circ} \mathrm{C}$ for 24 hours. Culture isolates were then identified based on conventional identification methods including Gram's staining and colony formation. A series of biochemical tests such as catalase, oxidase, urease, indole, citrate utilization, motility, and triple sugar iron test were done.

\section{Extended-Spectrum Beta Lacatamases Detection}

$E$. coli and $K$. pneumoniae were screened and confirmed for extended-spectrum beta lactamases (ESBLs) activity in accordance with Clinical and Laboratory Standards Institute guideline (CLSI) ${ }^{29}$. Initial ESBLs activity was determined by screening cefotaxime (CTX: $30 \mu$

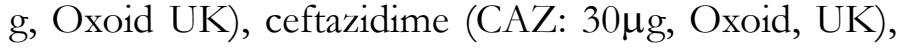


and ceftriaxone (CRO: $30 \mu \mathrm{g}$, Oxoid UK) using Mueller Hinton agar (MHA: Oxoid, UK) already inoculated with the isolates.

To improve sensitivity of ESBLs detection, more than one antibiotic disc were used as recommended by CLSI guidelines ${ }^{29}$. Freshly grown colonies were suspended into normal saline and the turbidity of the suspension was adjusted at $0.5 \mathrm{McF}$ arland's standard. The suspension was inoculated onto Mueller Hinton agar (MHA: Oxoid UK) with all three discs place at a gap of $20 \mathrm{~mm}$. Plates were then incubated for $18 \mathrm{hrs}$ at $37^{\circ} \mathrm{C}$. Isolates with reduced susceptibility to cefotaxime (zone diameter of $\leq 27 \mathrm{~mm}$ ), ceftazidime (zone diameter of $\leq$ $22 \mathrm{~mm}$ ), and ceftriaxone (zone diameter of $\leq 25 \mathrm{~mm}$ ) around the discs were suspected to be ESBLs produc$\operatorname{ers}^{29}$.

The double discs synergy method was employed for the confirmation of suspected ESBLs producers. This was done by testing the following antibiotic discs; cefotaxime (CTX: $30 \mu \mathrm{g}$, Oxoid, UK), ceftazidime (CAZ: 30 $\mu \mathrm{g}$, Oxoid, UK) and amoxycillin+clavulanic acid (AMC: 30 $\mu \mathrm{g}$, Oxoid, UK) on Mueller Hinton agar (MHA: Oxoid, UK). Amoxycillin+clavulanic acid disc was placed in the center of the Mueller Hinton agar plates. Cefotaxime and ceftazidime were placed at a distance of $20 \mathrm{~mm}$ from the amoxycillin+clavulanic acid disc. Plates were then examined after incubation for 24 hours at $37^{\circ} \mathrm{C}$ for an expansion of inhibition zone of the oxyimino- $\beta$ -lactam caused by the synergy of the clavulanate in the amoxycillin+clavulanic acid disc which was interpreted as ESBLs positive.

\section{Antibiotic Susceptibility Test}

Susceptibility testing of isolates to 7 antibiotics was performed using disc diffusion method. Isolates were enriched in peptone water for 24 hours after which $0.1 \mathrm{ml}$ was streaked onto Mueller Hinton agar (Oxoid, UK). The following antibiotics were used; cefoxitin (FOX: $30 \mu \mathrm{g}$, Oxoid, UK), cefotaxime (CTX: 30 $\mathrm{g}$, Oxoid, $\mathrm{UK})$, ceftazidime (CAZ: $30 \mu_{\mathrm{g}}, \mathrm{UK}$, Oxoid), gentamicin (GEN: $10 \mu \mathrm{g}$, Oxoid, UK), ciprofloxacin (CIP: $5 \mu \mathrm{g}$, Oxoid, UK), amoxycillin+clavulanic acid (AMC: $30 \mu \mathrm{g}$, Oxoid, UK) and imipenem (IPM: 10 $\mathrm{g}$, Oxoid, UK). Results were interpreted as resistant or susceptible based on the interpretative standard according to the clinical and laboratory standards institute (CLSI) manual29.

\section{Results \\ Demographic characteristics of patients}

Table 1 shows the age and sex distribution of participants. The age range of patients who participated in the study was between 17 to 72 years. Study population was predominantly females $(66.0 \%)$ with a male to female ratio of 1:1.9. During the study period, 200 urine samples were analysed. Forty-four samples were excluded because the causative pathogens of interest could not be identified. Consequently, $156(78.0 \%)$ cases were included in this study. The common most predominant causative pathogen was E. coli which accounted for 128 $(82.1 \%)$ cases. More isolates $(57.7 \%)$ were recovered from females with the least proportion of bacteria $(K$. pneumoniae) isolated in the male population (Table 2).

Table 1. Age and sex distribution of participants

\begin{tabular}{|l|l|l|l|}
\hline Age group (Years) & Male (\%) & Female (\%) & Total (\%) \\
\hline $17-21$ & 8 & 28 & 36 \\
\hline $22-26$ & 0 & 36 & 36 \\
\hline $27-31$ & 16 & 12 & 28 \\
\hline $32-36$ & 12 & 24 & 36 \\
\hline $37-41$ & 8 & 20 & 28 \\
\hline $42-46$ & 8 & 4 & 12 \\
\hline $47-51$ & 12 & 4 & 16 \\
\hline$>51$ & 4 & 4 & 8 \\
\hline Total & $68(34.0)$ & $132(66.0)$ & $200(100)$ \\
\hline
\end{tabular}


Table 2. Distribution of isolates among gender and study sites

\begin{tabular}{|c|c|c|c|}
\hline Characteristic & E. coli $(\%)$ & K. pneumoniae (\%) & Total (\%) \\
\hline \multicolumn{4}{|l|}{ Sex } \\
\hline Male & $56(43.8)$ & $10(35.7)$ & $66(42.3)$ \\
\hline Female & $72(56.2)$ & $18(64.3)$ & $90(57.7)$ \\
\hline \multicolumn{4}{|l|}{ Study site } \\
\hline MGH & $90(70.3 \%)$ & $20(71.4 \%)$ & $110(70.5 \%)$ \\
\hline $\mathrm{GCH}$ & 38 (29.7\%) & 08 (28.6\%) & 46 (29.5\%) \\
\hline
\end{tabular}

\section{Frequency of Isolates}

The frequency of isolates in relation to study sites is shown in table 3. A total number of $110(70.5 \%)$ isolates of both E. coli and K. pneumoniae were recovered from
MGH while $46(29.5 \%)$ isolates (E. coli and K. pneumoniae) were obtained from GCH. Higher percentages of $E$. coli $(70.3 \%)$ and K. pneumoniae $(71.4 \%)$ isolates recorded, were also from MGH.

Table 3. Antimicrobial susceptibility profile of ESBL isolates

\begin{tabular}{|c|c|c|c|}
\hline & & \multicolumn{2}{|c|}{ ESBL-producing bacteria $(n=78)$} \\
\hline & & E. coli $(\%)$ & K. pneumoniae (\%) \\
\hline Cefotaxime & $\begin{array}{l}\text { Resistance } \\
\text { Intermediate } \\
\text { Sensitive } \\
\end{array}$ & $\begin{array}{l}54(100) \\
- \\
- \\
\end{array}$ & $\begin{array}{l}24(100) \\
- \\
- \\
\end{array}$ \\
\hline Cefoxitin & $\begin{array}{l}\text { Resistance } \\
\text { Intermediate } \\
\text { Sensitive } \\
\end{array}$ & $\begin{array}{l}12(22.2) \\
04(7.4) \\
38(70.4)\end{array}$ & $\begin{array}{l}15(62.5) \\
05(20.8) \\
04(16.7) \\
\end{array}$ \\
\hline Ceftazidime & $\begin{array}{l}\text { Resistance } \\
\text { Intermediate } \\
\text { Sensitive } \\
\end{array}$ & $\begin{array}{l}43(79.6) \\
02(3.7) \\
09(16.7)\end{array}$ & $\begin{array}{l}10(41.7) \\
03(12.5) \\
11(45.8)\end{array}$ \\
\hline Imipenem & $\begin{array}{l}\text { Resistance } \\
\text { Intermediate } \\
\text { Sensitive } \\
\end{array}$ & $\begin{array}{l}12(22.2) \\
39(72.2) \\
03(5.6)\end{array}$ & $\begin{array}{l}24(100) \\
- \\
- \\
\end{array}$ \\
\hline $\begin{array}{l}\text { Amoxycillin+clavul } \\
\text { anic }\end{array}$ & $\begin{array}{l}\text { Resistance } \\
\text { Intermediate } \\
\text { Sensitive } \\
\end{array}$ & $\begin{array}{l}45(83.3) \\
09(16.7) \\
-\end{array}$ & $\begin{array}{l}20(83.3) \\
01(4.2) \\
03(12.5)\end{array}$ \\
\hline Ciprofloxacin & $\begin{array}{l}\text { Resistance } \\
\text { Intermediate } \\
\text { Sensitive } \\
\end{array}$ & $\begin{array}{l}45(83.3) \\
- \\
09(16.7)\end{array}$ & $\begin{array}{l}18(75.0) \\
04(16.7) \\
02(8.3) \\
\end{array}$ \\
\hline Gentamicin & $\begin{array}{l}\text { Resistance } \\
\text { Intermediate } \\
\text { Sensitive }\end{array}$ & $\begin{array}{l}27(50) \\
15(27.8) \\
12(22.2)\end{array}$ & $\begin{array}{l}16(66.7) \\
04(16.7) \\
04(16.7)\end{array}$ \\
\hline
\end{tabular}




\section{Isolation of ESBL-producing bacteria}

Expression of ESBLs was phenotypically detected by double discs synergy test methods. The total number of ESBL-producing isolates was 78 (Table 3). Out of these ESBL-producing isolates, E. coli accounted for $69 \%$ (54/78) whereas K. pneumoniae accounted for $31 \%$ (24/78).

\section{Antimicrobial Resistance of ESBL Isolates}

Majority of all ESBL-producing isolates displayed phenotypic resistance to three or more drugs. Escherichia coli isolates were found to be highly resistant to both beta lactam (cefotaxime, ceftazidime and amoxicillin clavulanic acid) and non-beta lactam (ciprofloxacin) antibiotics. Resistance to ciprofloxacin and gentamicin accounted for $83.3 \%$ and $50 \%$ respectively. All isolates of K. pneumoniae exhibited a $100 \%$ resistance to cefotaxime and imipenem. Isolates were also resistant to ciprofloxacin $(75 \%)$, cefoxitin $(62.5 \%)$, gentamicin (66.7) and amoxicillin clavulanic acid (83.3\%). Results on the antimicrobial susceptibility of these ESBL-producing isolates are summarized in table 3.

\section{Discussion}

The emergence and rapid spread of multi-drug resistant pathogens are of great concern worldwide; among them, ESBL-producing Enterobacteriaceae has been a major concern. During the past decades, ESBL-producing Gram-negative bacteria especially E. coli and K. pneumoniae have emerged as serious pathogens both in hospital and community acquired infections worldwide ${ }^{30}$. Developing countries are far behind in the fight against antimicrobial resistance with considerable efforts needed to reduce morbidity and mortality due to infection caused by these multi-drug resistant pathogens $\mathrm{s}^{31-33}$. Therefore, bacterial infection and antibiotic resistance surveillance are essential for effective management of infections.

In this study, the number of male patients to female patients ratio was 1:1.9. This concurred with findings from Nepal and Nigeria, that reported similar ration among patients suspected to have urinary tract infections ${ }^{30,34}$. This increase in the number of female participants may be due to involuntary recruitment bias. This study, similar to other studies, ${ }^{34}$ further showed that females were most affected among positive cases with higher isolation rates. Several predisposing factors such as increase in age, frequency of sexual activities and high parity have been attributed to the high infection rates among female patients ${ }^{35-38}$. Also, the short length of the urethra and it proximity to the anus, makes colonization with colonic Gram-negative bacteria possible ${ }^{39}$.
Findings in this study showed a high prevalence of infections among patients attending MGH (70.5\%) compared to patients in $\mathrm{GCH}$. The high prevalence reported in this study site can be attributed to higher intake of patients due to its location within a university community thus receiving higher numbers of patients.

In our study, E. coli was the predominant pathogen isolated with an isolation rate of $82.1 \%$. K. pneumoniae accounted for $17.9 \%$ of infection. This finding is consistent with previous studies which indicated that E. coli and $K$. pneumoniae were among Gram-negative pathogens associated with about $90 \%$ of both community and hospital acquired UTIs ${ }^{40,41}$. These bacterial pathogens have been associated with attributable mortality due to their high antibiotic resistance and thus categorised by the World Health Organization (WHO) as critical Gram-negative pathogens under surveillance. ${ }^{10}$ Other studies have reported E. coli as the most prevalent clinically important pathogen implicated in UTIs followed by K. pneumoniae ${ }^{42-45}$.

The true prevalence of ESBL is not well-known in Africa because of the paucity of studies in human and animal health. Nonetheless, studies have found that ESBL-producing bacteria are common and vary between countries of the continent ${ }^{46,47}$.

In our study, we identified $50 \%(78 / 156)$ of all isolates as ESBL-producers. This high rates observed is in contrast to previous studies ${ }^{48,49}$ where rates were reported to be as low as $2 \%$ in the Netherlands, $2.6 \%$ in Germany and $16 \%$ in Nigeria. However, studies by ${ }^{50,51}$ reported high rates of ESBL production. This observed rate may be attributed to the practices of self-medication and the less controlled use of antibiotics which are available over-the-counter in this region. Additionally, regulations promoting rational use of antibiotics are minimal or non-existent ${ }^{26,52}$. Sixty-nine per cent $(54 / 78)$ of E. coli and 31\% (24/78) of K. pneumoniae were identified as ESBL-producers and found to show resistance to three or more antibiotics.

Our study clearly revealed high resistance rates of ESBL- producing E. coli to ceftazidime (79.6\%), cefotaxime $(100 \%)$, amoxicillin clavulanic acid $(83.3 \%)$ and ciprofloxacin $(83.3 \%)$. This results are in agreement with studies conducted in Thailand where high resistance to ciprofloxacin, ceftazidime and cefotaxime were reported ${ }^{53,54}$. The high resistance observed in this study calls for serious concerns considering the fact that antibiotic use is less controlled in this sub-region. This gives room for self-medication and abuse due to easy availability of these antibiotics ${ }^{55}$.

African Health Sciences, Vol 21 Issue 2, June, 2021 
ESBL-producing K. pneumoniae isolates were found to be resistant to ciprofloxacin, cefoxitin, gentamicin, imipenem and amoxicillin clavulanic acid. All 24 isolates were resistant to cefotaxime. These findings are consonant with other research ${ }^{56}$. Carbapenems are regarded as the drugs of choice for treatment of infections caused by ESBL-producers. However, reports have indicated that carbapenemase producing Enterobacteriaceae isolates seem to be increasing in number in the last few years ${ }^{57,58,59}$. In this study, the tested ESBL-producing $K$. pneumoniae isolates showed high resistance rate for imipenem $(100 \%)$. This is in close conformity with the findings in the study conducted by Ferreira et al. ${ }^{59}$ from Brazil who reported $100 \%$ of K. pneumoniae strains were carbapenemase producers. A similar study by Nagaraj et al. ${ }^{60}$ also showed a resistance of $75 \%$ to carbapenems. This study highlights a worrying prevalence of ESBL-producing Gram-negative bacteria associated with urinary tract infections. Immediate action is therefore needed to prevent these resistant bacteria from spreading in both healthcare and community settings. Sustainable efforts at developing new antibiotics and vaccines should be encouraged to advance the containment of this threat. ${ }^{26}$ High antibiotic usage should also be reduced. This can be achieved through stewardship and guidance on appropriate use. Furthermore, routine surveillance of antimicrobial resistant isolates should be incorporated.

\section{Conflict of interest}

The authors declare that there is no conflict of interest.

\section{References}

1. Renner LD, Zan J, Hu LI, Martinez M, Resto PJ, Siegel AC, et al. Detection of ESKAPE bacterial pathogens at the point of care using isothermal DNA-based assays in a portable degas-actuated microfluidic diagnostic assay platform. Applied and Environmental Microbiology. 2017;83(4):e02449-16.

2. World Health Organization. Global incidence and prevalence of selected curable sexually transmitted infections-2008. WHO, Geneva, Switzerland, 2012.

3. Andersson DI, Hughes D. Microbiological effects of sublethal levels of antibiotics. Nature Reviews Microbiology. 2014;2:465-478.

4. Rice LB. Federal funding for the study of antimicrobial resistance in nosocomial pathogens: no ESKAPE. Journal of Infectious Diseases. 2008;197:1079-81.

5. Rice LB. Progress and challenges in implementing the research on ESKAPE pathogens. Infection Control and Hospital Epidemiology. 2010;31 Suppl 1:S7-10.
6. Pitout JD, Laupland KB. Extended-spectrum beta-lactamase-producing Enterobacteriaceae: an emerging public-health concern. Lancet Infectious Diseases. 2008;8(3):159-66.

7. Gulen TA, Guner R, Celikbilek N, Keske S, Tasyaran M. Clinical importance and cost of bacteremia caused by nosocomial multi drug resistant acinetobacter baumannii. International Journal of Infectious Diseases. 2015;38:32-5.

8. O’Neill, J. Tackling Drug-Resistant Infections Globally: Final Report and Recommendations. Review on Antimicrobial Resistance, 2016.

9. World Health Organization. Global Action Plan on Antimicrobial resistance. Geneva: WHO, 2015.

10. World Health Organization. Global Priority List of Antibiotic-Resistance Bacteria to Guide Research, Discovery, and Development of new Antibiotics. Geneva: WHO, 2017.

11. Jacobs AC, Hood I, Boyd KL, Olson PD, Morrison JM, Carson S, et al. Inactivation of Phospholipase D Diminishes Acinetobacter baumannii Pathogenesis. Infection and Immunity. 2010;78(5):1952-1962.

12. Kahrstrom CT. Entering a post-antibiotic era? $\mathrm{Na}$ ture Reviews Microbiology. 2013;11(3):146-146.

13. Singh N, Manchanda V. Control of multidrug-resistant gram-negative bacteria in low and middle-income countries-high impact interventions without much resources. Clinical Microbiology and Infection. 2017;23:216-8. 14. Bradford PA. Extended-spectrum beta-lactamases in the 21 st century: characterization, epidemiology, and detection of this important resistance threat. Clinical Microbiology Reviews. 2001;14:933-951.

15. Paterson DL, Bonomo RA. Extended-spectrum beta-lactamases: a clinical update. Clinical Microbiology Reviews. 2005;18:657-686.

16. Hawkey PM, Jones AM. The changing epidemiology of resistance. Journal of Antimicrobial Chemotherapy. 2009;64(Suppl. 1):3-10.

17. Dierikx CM, van Duijkeren E, Schoormans AHW, van Essen-Zandbergen A, Veldman K, Kant A, et al. Occurrence and characteristics of extended-spectrum- $\beta$-lactamase- and AmpC-producing clinical isolates derived from companion animals and horses. Journal of Antimicrobial Chemotherapy. 2012;67:1368-1374.

18. Geser N, Stephan R, Hächler H. Occurrence and characteristics of extended-spectrum $\beta$-lactamase (ESBL) producing Enterobacteriaceae in food producing animals, minced meat and raw milk. BMC Veterinary Research. 2012;8:21.

19. Lupindu, AM, Olsen JE, Ngowi HA, Msoffe PLM, Mtambo MM, Scheutz F, et al. Occurrence and char- 
acterization of Shiga toxin- producing Escherichia coli O157:H7 and other non-sorbitol-fermenting E. coli in cattle and humans in urban areas of Morogoro, Tanzania. Vector Borne Zoonotic Diseases. 2014;14:503-510.

20. Perovic O, Singh-Moodley A, Duse A, Bamford C, Elliott G, Swe-Han KS, et al. National sentinel site surveillance for antimicrobial resistance in Klebsiella pneumoniae isolates in South Africa, 2010-2012. South African Medical Journal. 2014;104(8):563-568.

21. Ronald A. The aetiology of urinary tract infection: traditional and emerging pathogens. American Journal of Medicine. 2002;113(Suppl. 1):14s-19s.

22. Flores-Mireles AL, Walker JN, Caparon M, Hultgren SJ. Urinary tract infections: Epidemiology, mechanisms of infection and treatment options. Nature Reviews Microbiology. 2015;13:269-284.

23. Gupta K, Hooton TM, Naber KG, Wullt B, Colgan $\mathrm{R}$, Miller LG, et al. International clinical practice guidelines for the treatment of acute uncomplicated cystitis and pyelonephritis in women: A 2010 update by the Infectious Diseases Society of America and the European Society for Microbiology and Infectious Diseases. Clinical Infectious Diseases. 2011;52:103-120.

24. Sobel JD, Kaye D. 74-Urinary Tract Infections. In Mandell, Douglas, and Bennett's Principles and Practice of Infectious Diseases, 8th ed.; Bennett JE, Dolin R, Blaser MJ, Eds.; Elsevier: Philadelphia, PA, USA. pp. 886-913.e3, ISBN 978-1-4557-4801-3, 2015.

25. World Health Organization. Antimicrobial Resistance Global Report on Surveillance. Geneva: WHO, 2014.

26. Founou RC, Founou LL, Essack SY. Clinical and economic impact of antibiotic resistance in developing countries: A systematic review and meta-analysis. PLoS One. 2017;12(12):e0189621.

27. Arzai AH, Adamu DJM. Prevalence of beta-lactamase Producers among randomly selected bacterial pathogens in Kano, Nigeria. Biological and Environmental Sciences Journal for the Tropics. 2008;5(3):218-223.

28. Okolo MO, Omatola CA, Ezugwu AI, Adejoh PO, Abraham OJ, Chukwuma OJT. Prevalence of malaria among pregnant women attending antenatal clinic in Grimard Catholic Hospital, Anyigba in Kogi State, Nigeria. Nature and Science. 2017;15:113-117.

29. Clinical and Laboratory Standards Institute. Performance standards for antimicrobial susceptibility testing. Twenty-fourth information supplement, CLSI document M100-S24. Clinical and Laboratory Standards Institute, Wayne, PA, USA, 2014.

30. Shakya P, Shrestha D, Maharjan E, Sharma VK, Paudyal R. ESBL production among E. coli and Kleb- siella spp. Causing urinary tract infection: A hospital based study. The Open Microbiology Journal. 2017;11:23-30. 31. Laxminarayan R, Sridhar D, Blaser M, Wang M, Woolhouse M. Achieving global targets for antimicrobial resistance. Science (New York, NY), 2016.

32. Huttner A, Harbarth S, Carlet J, Cosgrove S, Goossens $\mathrm{H}$, Holmes A, et al. Antimicrobial resistance: a global view from the 2013 World Healthcare-Associated Infections Forum. Antimicrobial Resistance and Infection Control. 2013;2:2-31.

33. Samuel S, Kayode O, Musa O, Nwigwe G, Aboderin A, Salami T, et al. Nosocomial infections and the challenges of control in developing countries. African Journal of Clinical Experimental Microbiology. 2010;11:102-9.

34. Giwa FJ, Ige OT, Haruna DM, Yaqub Y, Lamido TZ, Usman SY. Extended-Spectrum beta-lactamase production and antimicrobial susceptibility pattern of uropathogens in a Tertiary Hospital in Northwestern Nigeria. Annals of Tropical Pathology. 2018;9:11-6.

35. Rahn DD. Urinary tract infections: Contemporary management. Urologic Nursing Journal. 2008;28:333-41.

36. Foxman B, Barlow R, D’Arcy H, Gillespie B, Sobel JD. Urinary tract infection: Self-reported incidence and associated costs. Annals of Epidemiology. 2000;10:509-15. 37. Komala M, Kumar KS. Urinary tract infection: causes, symptoms, diagnosis and it's management. Indian Journal of Research in Pharmacy and Biotechnology. 2013;1:226-33.

38. Foxman, B. Epidemiology of urinary tract infections: Incidence, morbidity, and economic costs. American Journal of Medicine. 2002;113:5-11.

39. Forbes BA, Sahm DF, Weissfeld AS. Bailey \& Scott's Diagnostic Microbiology. 12th ed. USA: Mosby Elsevier, 2007.

40. Linhares I, Raposo T, Rodrigues A, Almeida A. Frequency and antimicrobial resistance patterns of bacteria implicated in community urinary tract infections: a ten-year surveillance study (2000-2009). BMC Infectious Diseases. 2013;13:19-33.

41. Farajnia S, Alikhani MY, Ghotaslou R, Naghili B, Nakhlband A. Causative agents and antimicrobial susceptibilities of urinary tract infections in the northwest of Iran. International Journal of Infectious Diseases. 2009;13:140-4.

42. Agyepong N, Govinden U, Owusu-Ofori A, Essack SY. Multidrug-resistant gram-negative bacterial infections in a teaching hospital in Ghana. Antimicrobial Resistance and Infection Control. 2018;7(37):1-8.

43. Gyasi-Sarpong CK, Nkrumah B, Yenli EMT-A, Appiah AA, Aboah K, Azorliade R, et al. Resistance pattern of uropathogenic bacteria in males with lower uri- 
nary tract obstruction in Kumasi, Ghana. African Journal of Microbiology Research. 2014;8:3324-9.

44. Azekhueme I, Moses AE, Abbey SD. Extended spectrum beta-lactamases in clinical isolates of Escherichia coli and Klebsiella pneumoniae from University of Uyo Teaching Hospital, Uyo-Nigeria. Journal of $A d-$ vances in Medical Pharmaceutical Sciences. 2005;2:117-25.

45. Ramesh N, Sumathi CS, Balasubramanian V, Palaniappan KR, Kannan VR. Urinary tract infections and antimicrobial susceptibility pattern of extended spectrum of beta lactamase producing clinical isolates. $A d-$ vances in Biological Research. 2008;2:78-82.

46. Founou LL, Founou RC, Allam M, Ismail A, Djoko CF, Essack SY. Genome Sequencing of Extended-Spectrum $\beta$-Lactamase (ESBL)-Producing Klebsiella pneumoniae Isolated from Pigs and Abattoir Workers in Cameroon. Frontiers in Microbiology. 2018;9:188.

47. Storberg V. ESBL $\square$ producing Enterobacteriaceae in Africa a non $\square$ systematic literature review of research published 2008-2012. Infection Ecology and Epidemiology. 2014;4:20342.

48. Bouchillon SK, Johnson BM, Hoban DJ. Determining incidence of extended spectrum $\beta$-lactamase producing Enterobacteriaceae, vancomycin-resistant Enterococcus faecium, and methicillin-resistant Staphylococcus aureus in 38 centres from 17 countries: the PEARLS study 2001-2002. International Journal of Antimicrobial Agents. 2004;24:119-124.

49. Mohammed, Y., G.B. Gadzama, S.B. Zailani, and A.O. Aboderin. 2016. Characterization of extended-spectrum beta-lactamase from Escherichia coli and Klebsiella species from North Eastern Nigeria. J. Clin. Diagn. Res. 10:7-10.

50. Tankhiwale, S.S., S.V. Jalgaonkar, S. Ahamad, and U. Hassani. 2004. Evaluation of extended spectrum beta lactamase in urinary isolates. Indian J. Med. Res. 120:5536.

51. Mathur P, Kapil A, Das B, Dhawan B. Prevalence of extended spectrum $\beta$-lactamase producing gram negative bacteria in a tertiary care hospital. Indian Journal of Medical Research. 2002;115:153-7.
52. Fadil AA, Abdelraheem AR, Abdel-Aziz AA, Swelam SH. ESBL-Producing E. coli and Klebsiella among Patients Treated at Minia University Hospitals. Journal of Infectious Diseases and Preventive Medicine. 2017;5(2):156.

53. Bubpamala J, Khuntayaporn P, Thirapanmethee K, Montakantikul P, Santanirand P, Chomnawang MT. Phenotypic and genotypic characterizations of extanded-spectrum beta-lactamase-producing Escherichia coli in Thailand. Infection and Drug Resistance. 2018; 11:21512157.

54. Sharma M, Pathak S, Srivastava P. Prevalence and antibiogram of Extended Spectrum $\beta$-Lactamase (ESBL) producing Gram negative bacilli and further molecular characterization of ESBL producing Escherichia coli and Klebsiella spp. Journal of Clinical and Diagnostic Research. 2013;7(10): 2173-2177.

55. Ocan M, Bwanga F, Bbosa GS, Bagenda D, Waako P, Ogwal-Okeng J, et al. Patterns and predictors of self-medication in northern Uganda. PLoS One. 2014;9:92323-30.

56. Founou RC, Founou LL, Allam M, et al. Whole Genome Sequencing of Extended Spectrum $\beta$-lactamase (ESBL)-producing Klebsiella pneumoniae isolated from Hospitalized Patients in KwaZulu-Natal, South Africa. Scientific Reports. 2019;9:62-66.

57. Falagas ME, Karageorgopoulos DE. Extended-spectrum beta-lactamase-producing organisms. Journal of Hospital Infections. 2009;73:345-54.

58. Bhaskar BH, Shenoy SM, et al. Molecular Characterization of Extended Spectrum $\beta$-lactamase and Carbapenemase Producing Klebsiella pneumoniae from a Tertiary Care Hospital. Indian Journal of Critical Care Medicine. 2019;23(2):61-66.

59. Ferreira RL, da Silva BCM, Rezende GS, et al. High prevalence of multidrug-resistant Klebsiella pneumoniae harbouring several virulence and beta-lactamase encoding genes in a Brazilian intensive care unit. Frontiers in Microbiology. 2019;9(3198):1-15.

60. Nagaraj S, Chandran SP, et al. Carbapenem resistance among Escherichia coli and Klebsiella pneumoniae in a tertiary care hospital, South India. Indian Journal of Medical Microbiology. 2012;30:93-95. 